\title{
Penerapan Deep Learning dalam Pendeteksian Autism Toddler
}

\author{
Diah Ayu Ambarsari, Ridan Nurfalah, Sandra Jamu Kuryanti \\ Mahasiswa Pasca Sarjana Ilmu Komputer, STIMIK Nusa Mandiri, Indonesia
}

\section{KEYWORDS}

Autism, deep learning, todller,

\section{CORRESPONDENCE}

Phone: 082134079698

E-mail: diah.das@bsi.ac.id

\section{PENDAHULUAN}

Kesehatan adalah satu hal yang sangat penting . Setiap manusia dapat mengalami gangguan kesehatan terutama pada anak. Kesehatan anak merupakan merupakan impian setiap orang tua. Selama masa pertumbuhan anak akan mengalami beberapa gangguan yang dapat menghambat perkembanganya. Orang tua harus lebih peka dan mempunyai pengetahuan luas dalam kesehatan . Permasalahan yang sering terjadi yaitu orang tua tidak mengetahi gejala-gejala awal autis yang terjadi pada buah hati, jadi banyak orang tua menganggap kalau anaknya baikbaik saja , keadaan ini memperlambat proses diagnosis , padahal ganggua autis dapat di deteksi sejak dini dengan melihat kebiasaan tumbuh kembang anak setiap harinya.

Menurut Thabta dalm jurnalnya Farhan Autistik Spektrum Disorder (ASD). ASD adalah gangguan mental yang membatasi penggunaan linguistik, komunikatif, kognitif, keterampilan, serta keterampilan sosial dan kemampuan. Baru- baru ini, ASD telah dipelajari dalam perilaku sains menggunakan metode cerdas berbasis pembelajaran mesin (machine learning) untuk mempercepat waktu screening atau meningkatkan kepekaan, spesifisitas atau akurasi proses diagnosis. Pembelajaran mesin https://doi.org/10.30743/infotekjar.v4i1.1593

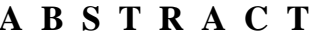

Kesehatan adalah satu hal yang sangat penting . Setiap manusia dapat mengalami gangguan esehatan terutama pada anak. Kesehatan anak merupakan merupakan impian setiap orang menghambat perkembanganya. Orang tua harus lebih peka dan mempunyai pengetahuan luas gejala awal autis yang terjadi pada buah hati, jadi banyak orang tua menganggap kalau anaknya baik-baik saja, keadaan ini memperlambat proses diagnosis , padahal ganggua autis dapat di deteksi sejak dini dengan melihat kebiasaan tumbuh kembang anak setiap cepat, karena dengan penanganan autis secara tepat dan cepat akan membantu penderita penyakit autis penulis melakukan penelitian dengan metode baru. Dalam studi sebelumnya fadli Fayes Tahbatan melakukan penelitian untuk mendeteksi apakah anak tersebut menderita autis atau tidak menggunakan alat. Namun hanya menghasilkan data set ., ternyata memiliki ini menggunakan metode deep learning dan menguji tingkat keakuratan, aplikasi yang model prediksi dari data set yang di peroleh Nilai akurasi yang di dapat dari pengolahan cukupbai adapun accuracy $=98,96 \%$ precision $=96,74 \% \quad$, recall $=98,49 \%$ dengan AUC sebesar $=0.90$

Kata Kunci : Autism, deep learning, todller

menganggap masalah diagnosis ASD sebagai tugas klasifikasi dalam model prediktif yang dibangun berdasarkan kasus historis dan kontrol [1].

Hasil penelitian dari Fadi Frazes Thabata sudah ada penelitian yang membahas mengenai metode pedeteksi autis secara dini bagi anak menggunakan suatu alat [2]

Pada kali ini penulis ingin meneliti Autistic Spectrum Disorder Screening toddler dimana penulis ingin mengkaji autism toddler dengan metode deep learning dengan akurat. Agar autism dapat di deteksi secara dini, sehingga dapat di tangani secara tepat.

\section{LANDASAN TEORI}

\section{Autis}

Adalah satu gangguan kejiwaan primer adalah Autistik Spektrum Disorder (ASD). ASD adalah gangguan mental yang membatasi penggunaan linguistik, komunikatif, kognitif, keterampilan soaial dan kemampuan [1].

Autisme berasal dari kata "autos" yang berarti segala sesuatu yang mengarah pada diri sendiri. Dalam kamus psikologi umum (1982), autisme berarti preokupasi terhadap pikiran dan khayalan sendiri atau dengan kata lain lebih banyak berorientasi kepada pikiran subyektifnya sendiri daripada melihat kenyataan 
atau realita kehidupan sehari-hari. Oleh karena itu penderita autisme sering disebut orang yang hidup di "alamnya" sendiri [3]

\section{Depp Learning}

Deep Learning merupakan bagian dari Machine Learning yang terdiri dari banyak lapisan (hidden Layer)dan membentuk tumpukan, lapisan tersebut adalah sebuah algoritma atau metde yang melakukan klasifikasi perintah yang diinputkan hingga menghasilkan outpt.[4].

Deep Learning adalah teknik dalam NN yang menggunakan teknik tertentu seperti Restricted Boltzmann Machine untuk mempercepat proses pembelajaran dalam NN yangmenggunakan lapis yang banyak atau lebih dari 7 lapis, waktu yang digunakan untuk training semakin efektif karena hilangnya gradien pada propagasi balik akan semkain renah[5].

\section{Objek Penelitian}

Objek penelitian ini adalah toodler yang mempunyai permasalah gangguan tumbuh kembag yang di peroleh dari data set.

Pada penelitian ini data yang digunakan adalah data Autism Screening Data for Tooddlers yang didaptkan dari Kaggel(https://www.kaggle.com/fabdelja/autism-screening-fortoddlers).

\section{METODE}

Dalam penelitian ini melalui beberapa tahap yang harus dilewati, tahapan pada penelitian ini digambarkan pada gambar berikut:

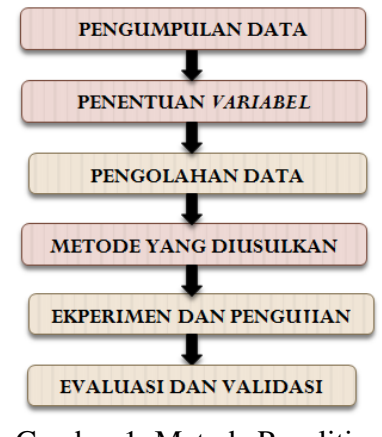

\section{Pengunpulan Data}

Kegitaan penelitian yang terpenting adalah pengumpulan data., pengumpulan data harus di tangani dengan serius agar memperoleh hasil yang sesuai dengan kegunaannya yaitu pengumpulan variabel yang tepat [6]. Pengumpulan data memerlukan kejelihan agar memperoleh hasil dengan tingkat validasi yang tepat. Data dari penelitian ini digunakan adalah data Autism Screening Data for Tooddlers yang didaptkan dari Kaggel (https://www.kaggle.com/fabdelja/autism-screening-fortoddlers). Data yang dikumpulkan dalam penelitian ini berparameter analisis kotak mata dalam kehiduan sehari-hari pada anak. Data Terkumpul sebanyak 1055 data dengan 728 anak dinyatakan mengalami gangguan autis dan 884 anak dinyatakan tidak mengalami gangguan autis. Data ini mempunya 17 atribut.

\section{Pemilihan Variabel}

Setelah Pengumpulan data dilakukan langkah selanjutnya adalah penentuan variabel yang akan diolah agar menjadi informasi yang akurat. Variabel sangat berpengaruh dalam mendeteksi gejala autisme pada balita. Apakah pola yang dihasilkan deep learning dapat mendeteksi dengan akurat ? Permasalahan tersebut Variabel yang digunakan penulis adalah sebagai berikut

1. Bagaimana hasil pengukuran data set dengan menggunakan algoritma deep learning?

2. Bagaimana Hasil pengukuran data set dengan menggunakan algoritma deep learning?

3. Bagaimana pola yang dihasilkan deep learning?

Dengan adanya pertanyaan tersebut penulis menentukan 10 variabel dari 17 variabel agar mengahasilkan data yang benarbenar akurat, adapun variabel yang di tentukan sebagai berikut :

Tabel 1. Tabel Variabel

\begin{tabular}{|l|l|}
\hline $\begin{array}{l}\text { Variabelin } \\
\text { Dataset }\end{array}$ & Column A $(\boldsymbol{t})$ \\
\hline A1 & $\begin{array}{l}\text { Apakah anak anda melihat anda ketika di } \\
\text { panggil? }\end{array}$ \\
\hline A2 & $\begin{array}{l}\text { Seberapa mudah anda melakukan kontak } \\
\text { mata dengan anak anda? }\end{array}$ \\
\hline A3 & $\begin{array}{l}\text { Apakah anak menunjukkan menginginkan } \\
\text { sesuatu? }\end{array}$ \\
\hline A4 & $\begin{array}{l}\text { Apakah anak menunjukkan minat dengan } \\
\text { yang sama dengan anda? }\end{array}$ \\
\hline A5 & $\begin{array}{l}\text { Apakah anak Anda berpura-pura? (mis. } \\
\text { merawatboneka, di } \\
\text { teleponmainan) }\end{array}$ \\
\hline A6 & $\begin{array}{l}\text { Apakah anak anda mengikuti arah yang } \\
\text { anda cari? }\end{array}$ \\
\hline A7 & $\begin{array}{l}\text { Jika anda/ orang lain dalam keluarga } \\
\text { merasa kesal apakah anak anda } \\
\text { menunjukkan tanda-tanda ingin menghibur? }\end{array}$ \\
\hline A8 & $\begin{array}{l}\text { Apakah anda menggambarkan kata-kata } \\
\text { pertama anak anda? }\end{array}$ \\
\hline A9 & $\begin{array}{l}\text { Apakah anak anda menggunakan gerakan } \\
\text { sederhana? ( Selamnat tinggal, dll.) }\end{array}$ \\
\hline A10 & $\begin{array}{l}\text { Apakah anak anda tidak melihat apapun } \\
\text { tanpa tujuan yang jelas? }\end{array}$ \\
\hline
\end{tabular}

\section{Pengolahan Data}

Setelah variabel di tentukan maka langkah selanjutnya yang dilakukan penulis adalah mengolah data. Pengolahan data menggunakan tols rapid miner. Dalam pengolahan ini akan mengahasilan hasil accurcy.

Data yang dikumpulkan dalam penelitian ini berparameter analisis kotak mata dalam kehiduan sehari-hari pada anak. Data Terkumpul sebanyak 1055 data dengan 728 anak dinyatakan mengalami gangguan autis dan 884 anak dinyatakan tidak mengalami gangguan autis. Data ini mempunya 17 atribut

\section{Metode Yang Diusulkan}

Metode analisa merupakan metode yang diusulkan untuk mengetahui berapa besar tingakat akurasi dari deep learningdengan menggunakan komputasi rapid miner 9.0, hasil yang di peroleh dari analisa pengujian ini akan dijakikan dasae penentuan diagnosis autis pada anak . 


\section{Eksperimen dan Pengujian Methode}

Data yang digunakan sebesar 1000 data akan dibagi menjadi 2 yaitu $80 \%$ untuk training set dan $20 \%$ untuk testing. Kemudian data training di apilkasikan ke dalam metode, setelah itu dilakukan pengujian menggunakan model yang digunakan, memasukkan data training ke dalam model dan menguji menggunakan Raid Miner.

\section{Evaluasi \& Validasi}

Evaluasi dan validasi yang di gunakan dalam penelitian ini menganalisa hasil kerja. Validasi yang di lakukan untuk mengukur hasil prediksi adalah sebagai berikut :

\section{Cross Validation}

Cross validation adalah pengujian standar yang dilakukan untuk memprediksi error rate. Data training dibagi secara random ke dalam beberapa bagian dengan perbandingan yang sama kemudian error rate dihitung bagian demi bagian, selanjutnya hitung rata-rata seluruh error rate untuk mendapatkan error rateuntuk mendapatkan error rate secara keseluruhan[7].

Pengukuran Menggunakan ROC Curve

Menurut Gornmescu dalam jurnal leidiyana Untuk klasifikasi data mining, nilai AUC dapat dibagi menjadi beberapa kelompok [7] :

a. $0.90-1.00=$ klasifikasi sangat baik

b. $0.80-0.90=$ klasifikasi baik

c. $0.70-0.80=$ klasifikasi cukup

d. $0.60-0.70=$ klasifikasi buruk

e. $0.50-0.60=$ klasifikasi salah Berdasarkan.

\section{HASIL DAN PEMBAHASAN}

Dari hasil Penelitian ini menggunakan 1000 record yang terdeteksi penyakit autis maupun tidak terdeteksi penyakit autis, yang diperoleh dari Kaggel (https://www.kaggle.com/fabdelja/autism-screening-fortoddlers). Semua atribut pada data terdiri dari 10 atribut, dimana 9 atribut merupakan prediktor dan 1 atribut label. Pengolahan data membuat model dengan algoritma deep learning, sama dengan algoritma pada umumnya, proses pengujian kali ini menggun akan rapid miner, model seperti gambar di bawah ini :

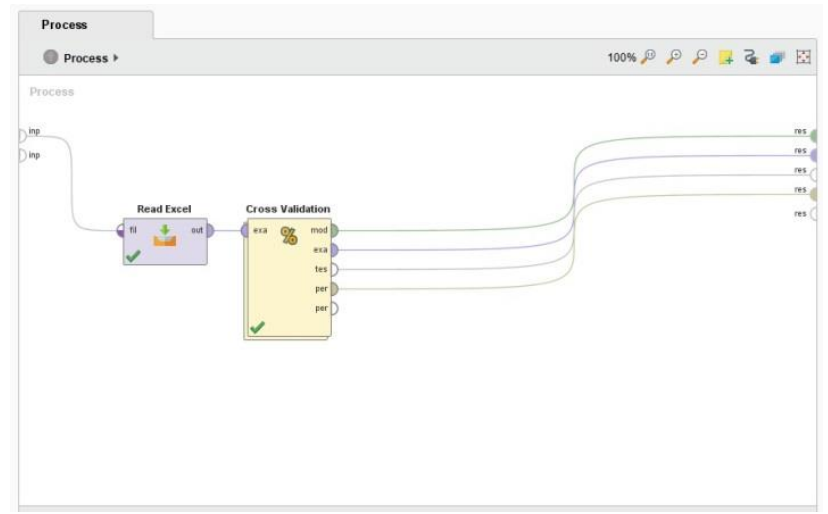

Sumber : (sari,2019)

Gambar 2. Desain Model Deep Learning

Pengujian model Deep Learnig dengan menggunakan testing dan validasi dapat menghasilkan nilai accuracy $=98,96 \%$, precission $=96,74 \%$, dan recall $=98,48 \%$ dengan AUC sebesar $=0,90$, seperti pada gamabar berikut :

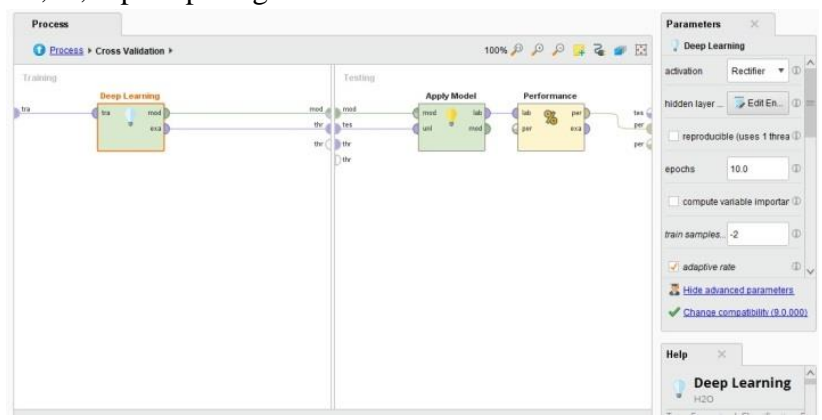

Sumber : (sari,2019)

Gambar 3. Desain Model Testing Deep Learning

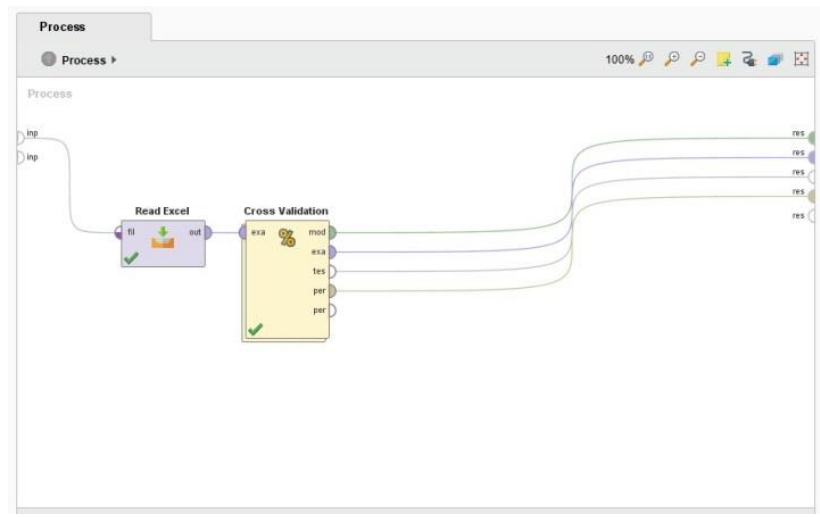

Sumber : (sari,2019)

Gambar4. Desain Validasi Deep Learning

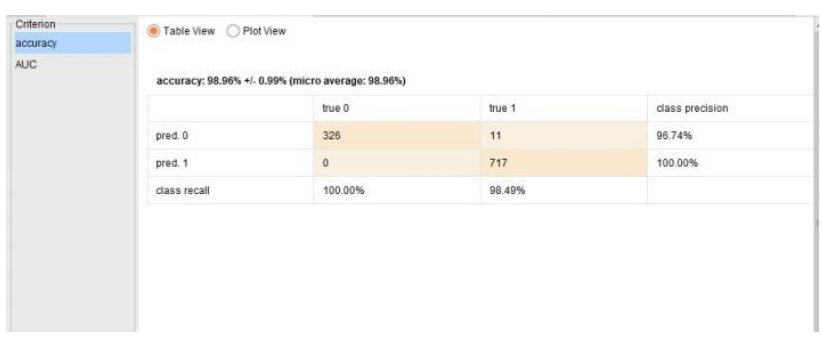

Sumber : (sari,2019)

Gambar 5. Nilsi Accuracy dari Deep Learning

Berdasarkan Gambar 5. Dapa kita ketahui bahwa hasil nilai accuracy $=98,96 \%$, ini menunjukkan hasil akurasi yang di peroleh termasuk baik.

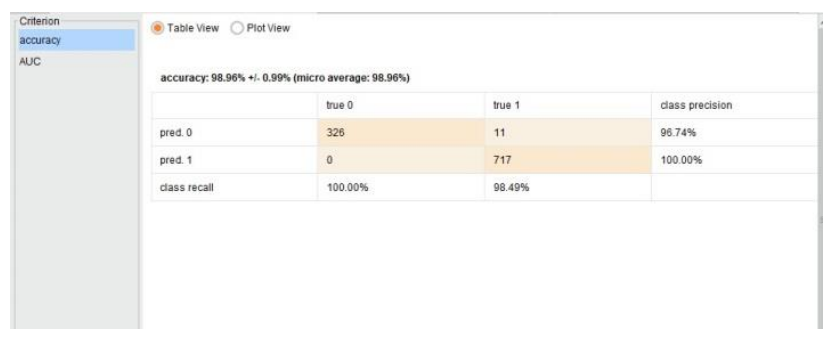

Sumber : (sari,2019)

Gambar 6. Nilai Accuracy dari Deep Learning

Berdasarkan gambar 6. Diperleh bahwa hasil precision dari metode deep learning sebesar $=96,74 \%$ bahwasanya nilai akurasin yang di peroleh pada pengolahan ini termasuk dalam kaegori baik.

https://doi.org/10.30743/infotekjar.v4i1.1593 


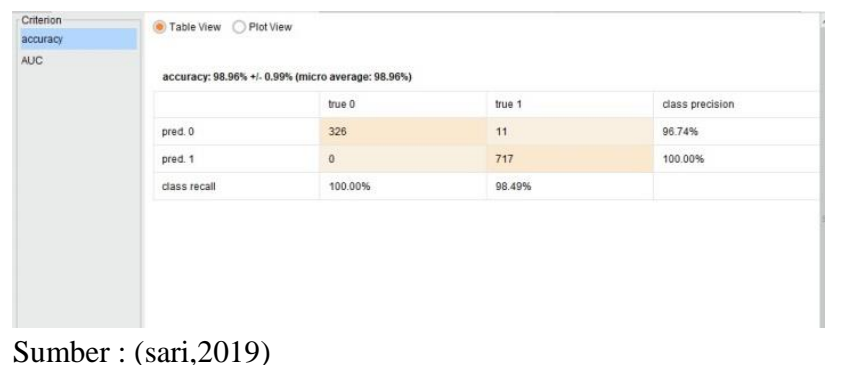

Gambar 7. Nilai Accuracy dari Deep Learning

Berdasarkan Gambar 7 . Diperoleh bahwa hasil Recall dari metode klasifikasi Deep Learning sebesar $=98,49 \%$ ini menunjukkan bahwa hasil akurasi yang diperoleh masuk dalam kategori baik

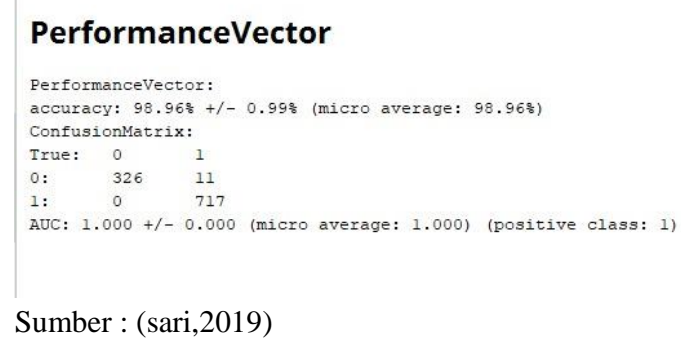

\section{PerformanceVector}

PerformanceVector:

Gambar 8. Nilai Accuracy dari Deep Learning

Gambar 8 memberikan informasi secara keseluruhan tentang hasil dan validasi dengan metode deep learning , hasil accuracy, preciticion dan recall, terdapat niali AUC dan informasi penting dalam performance vector ini yaitu confusion matrix pada masing-masing kategori sehat dan anak dengan nilai jelas.

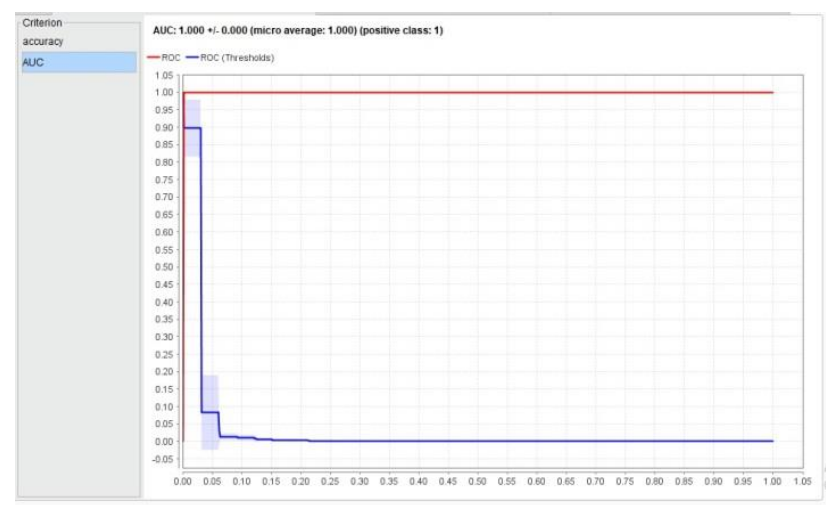

Sumber : (sari,2019)

Gambar 9. Nilai Accuracy dari Deep Learning

Gambar 9. Mengammmbarkan grafik area under curve dengan hasil validasi deep learning sebesar $=0,90$.

\section{KESIMPULAN}

Berdasarkan penelitian yang telah dilakukan menggunakan tools rapid miner 9.0 terdapat data menggunakan 1055 record yang terdeteksi penyakit autis maupun tidak terdeteksi penyakit autis, yang diperoleh dari Kaggel (https://www.kaggle.com/fabdelja/autism-screening-fortoddlers). Semua atribut pada data terdiri dari 10 atribut, dimana 9 atribut merupakan prediktor dan 1 atribut label. Pengolahan data membuat model dengan algoritma deep learning menghasilkan nilai accuracy $=98,96 \%$ precision $=96,74 \% \quad$, recall $=98,49 \%$ dengan $A U C$ sebesar $=0.90$ yang menujukan hasil klasifikasinya baik, sehingga paseien denga paremeter kontak mata dalam komunikasi yang dapat di predikid mana saja yang merupakan mengalamimi gangguan perkembangan anak yaitu autis, sehingga pola ini dapat dapat digunakan sebagai tolak ukur diagnosis sehingga dapat di deteksi lebih dini dan dapat di tangani sejak dini, semakin cepat di tangani kemingkinan beasr akan kembali normal.

\section{DAFTAR PUSTAKA}

[1] O. Farhan and A. Subekti, "Permodelan Prediktif Autistic Spectrum Disorder Dengan Algoritma C.45," J. Techno Nusa Mandiri, vol. 15, no. 2, p. 99, 2018.

[2] F. Thabtah, "Autism spectrum disorder screening: Machine learning adaptation and DSM-5 fulfillment," ACM Int. Conf. Proceeding Ser., vol. Part F129311, pp. 1-6, 2017.

[3] E. A. Yusuf, “Autisme masa anak," pp. 1-17, 2003.

[4] R. D. Nurfita and G. Ariyanto, "Implementasi Deep Learning Berbasis Tensorflow Untuk Pengenalan Sidik Jari," J. Emit., vol. 18, no. 01, pp. 22-27, 2018.

[5] A. Ahmad, "Mengenal Artificial Intelligence, Machine Learning, Neural Network, dan Deep Learning," $J$. Teknol. Indones., no. October, p. 3, 2017.

[6] "Instrumen Pengumpulan Data," Instrumen Pengumpulan Data, pp. 1-20, 2019.

[7] H. Leidiyana, "Penerapan Algoritma K-Nearest Neighbor Untuk Penentuan Resiko Kredit Kepemilikan Kendaraan Bemotor," Penelit. Ilmu Komput. Sist. Embed. dan Log., vol. 1, no. 1, pp. 65-76, 2013. 